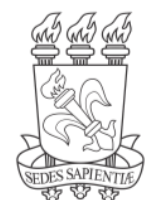

Nietzsche na fenomenologia

\title{
A figura de Nietzsche nos Cadernos Negros (1931-1948) de Heidegger. Uma abordagem hermenêutica
}

\author{
Nietzsche's presence in Heidegger's Black Notebooks (1931-1948). \\ An hermeneutical approach
}

\author{
Anna Luiza Coli'i(i), Giovanni Jan Giubilato "ID \\ 'Bergische Universität Wuppertal / Charles University Prague \\ "Universidade Federal de Lavras, Lavras, MG, Brasil
}

\section{RESUMO}

O presente ensaio aborda a presença de Nietzsche nos Cadernos negros de Heidegger com o intuito de esclarecer e analisar o papel filosófico que Nietzsche aí desempenha. A partir de ferramentas hermenêuticas básicas para a leitura e interpretação do conjunto dos textos que compõem o conjunto chamado Cadernos negros, composto de textos enigmáticos e únicos em relação ao corpus heideggeriano, a figura de Nietzsche aparece não apenas como um centro de referência privilegiado para o pensamento heideggeriano da década de 1930-40, mas também, e principalmente, como o impulso fundamental da profunda reformulação de suas coordenadas principais.

Palavras-chave: Heidegger; Nietzsche; Cadernos Negros; Hermenêutica

\section{ABSTRACT}

The following essay approaches Nietzsche's presence in Heidegger's Black Notebooks in order to clarify and analyze the particular philosophical role Nietzsche plays in them. Starting with the definition of basic hermeneutical tools for reading and interpreting those hermetic and certainly unique texts in the Heideggerian corpus, Nietzsche's figure emerges not only as a privileged reference center for the Heideggerian thought in the 1930s and 40s, but also and mainly as a fundamental impulse for a profound reformulation of its main coordinates.

Keywords: Heidegger; Nietzsche; Black Notebooks; Hermeneutics 


\section{INTRODUÇÃO}

A hermenêutica se consolidou na tradição filosófica ocidental como a arte de ler e interpretar textos, originalmente o texto sagrado, posteriormente os textos em geral. Na obra fundamental da hermenêutica contemporânea, Verdade e método, Gadamer nos ensina que toda aproximação a um texto, bem como toda interpretação de seu sentido, deve ser balizada por uma pergunta-guia [Leitfrage], por uma "compreensão preliminar" que determina a direção e o modo da aproximação àquele "mundo novo" ao qual o texto nos conduz. Compreender um texto significa, nesse contexto, interrogar seu sentido, abrir-se à presença e ao encontro de um "outro" inicialmente obscuro, mas jamais inteiramente ignorado e desconhecido. O encontro com as tramas inexploradas de um novo texto e seus horizontes recônditos de significação, encontro este que ampara o fenômeno da compreensão, depende, por sua vez, do momento de abertura ao outro que inaugura a possibilidade de uma relação dialógica entre o leitor e o texto lido. A abertura do espaço hermenêutico no qual a compreensão do sentido e o diálogo de leitor e texto se realizam não é o resultado nem da pretensão de neutralidade diante do conteúdo da obra, nem de um cancelamento objetivo do horizonte de compreensão que caracteriza toda e qualquer interpretação. Antes, como afirma Gadamer com sua doutrina da reabilitação dos preconceitos, a abertura do espaço hermenêutico depende de uma incorporação matizada das opiniões prévias e dos próprios preconceitos. A experiência hermenêutica pressupõe que o texto a ser compreendido necessariamente se insira numa situação previamente determinada por opiniões e posturas que servirão de guia, para o leitor, à exploração do sentido do texto lido.

A fundação ontológica dessa estrutura de compreensão, junto à descrição fenomenológica da "pré-compreensão", que inaugura a possibilidade da abertura ao texto e, por conseguinte, de sua aproximação, na medida em que procede a partir de uma "pergunta-guia", é um dos feitos mais louváveis de Ser e tempo de Heidegger, o notável mestre de Gadamer nos idos anos de 1920. O célebre $\$ 2$ de Ser e tempo inova ao apresentar uma estrutura formal de toda e qualquer pergunta e, de modo ainda 
mais específico, "o que em geral pertence a uma pergunta"11. Perguntar significa, em primeiro lugar, abrir um espaço de procura: cada pergunta é uma pergunta sobre algo, ou seja: uma busca por algo. Em todo perguntar devemos distinguir, portanto, três elementos fundamentais, constituintes da estrutura formal de toda pergunta:

\begin{abstract}
"aquilo de que se pergunta" , ou seja aquilo que é buscado pela pergunta [das Gefragte]; e todavia, considerando que "todo perguntar por... é, de algum modo, um perguntar $a . . .{ }^{\prime 3}$, o segundo elemento da estrutura formal de cada pergunta é precisamente "aquilo a que se pergunta"4 [das Befragte], seguindo o significado do verbo transitivo alemão befragen, que significa "interrogar ou consultar alguém (a respeito de algo)"; por fim, temos "aquilo que se pergunta" ${ }^{\text {, ou seja }}$ "aquilo para que propriamente se tende", aquilo "no qual o perguntar atinge a sua meta" [das Erfragte].
\end{abstract}

A exposição que a seguir se pretende da hermenêutica dos Cadernos negros e do papel que Nietzsche aí desempenha está estruturada em três momentos, de modo a reproduzir essa estrutura hermenêutica fundamental de todo interrogar. Tal estrutura se deixa indicar da seguinte forma:

1) o buscado pela pergunta, ou aquilo sobre o que perguntamos aqui é Nietzsche;

2) o interrogado, ou seja, aquele a quem interrogamos pela figura de Nietzsche é esse conjunto peculiar de textos que conhecemos como Cadernos negros;

3) o que está em questão nessa busca, nessa interrogação dos Cadernos negros pela figura de Nietzsche é, por fim, a própria filosofia de Heidegger em seu confronto com Nietzsche.

Seguindo esta estrutura, portanto, iniciaremos o texto por uma breve contextualização do que são os Cadernos negros de Heidegger através da figura de Nietzsche (I); em seguida, passamos à problemática hermenêutica fundamental em relação à novidade que esse conjunto de textos introduz no espectro da interpretação e recepção da obra de Heidegger. Essa problemática é introduzida pela pergunta sobre

\footnotetext{
1 HEIDEGGER, Ser e tempo, 39.

${ }^{2}$ HEIDEGGER, Ser e tempo, 41.

${ }^{3}$ HEIDEGGER, Ser e tempo, 41.

${ }^{4}$ HEIDEGGER, Ser e tempo, 41.

${ }^{5}$ HEIDEGGER, Ser e tempo, 41.
} 
"como devemos ler os Cadernos negros"? (II); passaremos, então, à análise referente aos primeiros cadernos publicados, i.e., a uma análise ainda parcial (frente ao material total dos Cadernos) da figura de Nietzsche que esses textos delineiam (III) e, por fim, pretendemos chegar ao problema fundamental que se revela à interrogação do papel desempenhado por Nietzsche no conjunto da obra (IV). Isso significa que a interpretação da figura de Nietzsche à qual esse caminho hermenêutico nos conduz diz respeito a uma interpretação imanente, i.e., interior ao pensamento de Heidegger. Nossa intenção é a de trazer ao debate alguns pontos fundamentais do confronto profundo e até mesmo visceral que Heidegger estabeleceu com o pensamento de Nietzsche, do qual os Cadernos negros nos dão um testemunho até então desconhecido. Tal confronto assumiu traços de um duelo de morte que levou Heidegger a uma profunda crise pessoal e filosófica, sobre a qual nos deixou afirmações sombrias como: "tenho a impressão de que cresço apenas em raízes e não mais como ramagem", ou "Nietzsche me destruiu!"6.

\section{OS CADERNOS NEGROS}

O início da década de 1930 trouxe consigo uma grande virada no pensamento de Heidegger. A assim chamada Kehre produziu uma transformação radical no modo e no significado da pergunta pelo ser, meta inconteste de todos seus esforços filosóficos até então, "última quimera com a qual vale a pena sonhar" 7 . A nova forma de pensamento inaugurada nos anos 1930 assumiu a tarefa de justificar o fracasso teórico de Ser e tempo, projeto que padeceu de uma dolorosa - e precoce - interrupção ainda na segunda seção de sua primeira parte, permanecendo inacabado. As razões de tal interrupção remontam, como Heidegger afirmou posteriormente ${ }^{8}$, à incapacidade do

\footnotetext{
${ }^{6}$ HEIDEGGER \& JASPERS, Correspondencia (1920-1963), 128. As traduções para o português, salvo indicação de traduções já publicadas, são de nossa autoria.

${ }^{7}$ VOLPI, La selvaggia chiarezza, 61.

${ }^{8}$ Cf. HEIDEGGER, Carta sobre o humanismo.
}

Voluntas, Santa Maria, v.12, n.1, p. 01-26, jan./abril., 2021 
pensamento e à insuficiência da linguagem metafísica, incapazes de tematizar o ser sem cair na armadilha de transformar o ente no ponto de Arquimedes da interrogação, mesmo que o ente em questão fosse o ente privilegiado que é o Dasein.

É o próprio Heidegger quem, após a guerra, faz referência à "virada" que, em seu pensamento, sinalizaria a passagem do projeto da ontologia fundamental de Ser $e$ tempo, ainda centrada no Dasein como ente privilegiado, ao pensamento do próprio ser, agora compreendido como acontecimento apropriador (Ereignis). Na Carta sobre o Humanismo de 1947, Heidegger afirma que a razão pela qual a terceira seção da primeira parte de Ser e Tempo não foi impressa se deve ao fato de que, à época de sua publicação, ele ainda não fora capaz de "repetir e acompanhar de modo satisfatório esse outro modo de pensar" ${ }^{9}$ o qual, já ao fim da parte publicada de Ser e Tempo, "abandona a subjetividade" 10 e realiza uma reviravolta na qual "tudo se inverte [se revira]"11 [Hier kehrt sich das Ganze um].

Segundo sua autointerpretação, a conferência Sobre a essência da verdade, realizada em 1930, mas publicada apenas em 1943, já oferecia um olhar sobre o novo e mais radical pensamento da virada: a inversão no caminho que, como as ranhuras nas montanhas, dão voltas e voltas mas apontam sempre para um mesmo destino, levando ao cume - ao ser, portanto.

A passagem de uma perspectiva ontológico-transcendental à nova visão do ser, agora entendido como acontecimento-apropriativo, é assinalada de modo implacável no curso de verão de 1935, Introdução à metafísica, no qual encontramos uma menção aparentemente descontextualizada ao Nacional-socialismo e à "verdade e grandeza intrínsecas desse movimento"12, sobrepostas à visão cosmopolítica de uma Europa

\footnotetext{
${ }^{9}$ HEIDEGGER, Carta sobre o humanismo, 47.

10 HEIDEGGER, Carta sobre o humanismo, 47.

11 HEIDEGGER, Carta sobre o humanismo, 47.

12 HEIDEGGER, Einführung in die Metaphysik (GA 40), 208. Nesse ponto seria extremamente produtivo explorar a conexão entre os temas "Heidegger e o nacional-socialismo" e "Nietzsche e o nacionalsocialismo". Obviamente, isso é algo que vai além dos limites e das possibilidades do presente artigo. Contudo, para este momento, lembramos apenas a persistência da mesma acusação de vários tipos de "vínculos" com o nacional-socialismo: no caso de Nietzsche, por meio de apropriações livres e até mesmo "selvagens" das noções de Übermensch (Além-do-humano) e Wille zur Macht (Vontade de poder), e no
} 
"espremida entre a Rússia de um lado, e a América, de outro"13 - "polos" estes que seriam, "de uma perspectiva metafísica, uma mesma coisa". ${ }^{14}$

O pano de fundo tanto obscuro quanto coerente dessas afirmações, aparentemente fora do âmbito de uma reflexão propriamente filosófica e, nesse sentido, aparentemente deslocadas de todo núcleo filosófico da filosofia heideggeriana - afinal, o que o ser poderia ter a ver com a Rússia ou com a América? -, insere-se de modo surpreendente nas tramas dos Cadernos negros, nos quais encontramos diversas afirmações análogas e todavia extensivas à questão judaica e seu papel na história do Seer. ${ }^{15}$ No contexto dos Cadernos negros, portanto, essa dimensão aparentemente extra-filosófica reencontra as bases político-metafísicas que a sustentam e the conferem relevância filosófica à medida em que desolculta a articulação dos atores políticos na história do Seer. ${ }^{16}$ Afinal, não seria um mero acaso que Heidegger iniciara a redação dos Cadernos negros justamente nessa fase crucial do seu pensamento, do início da década de 1930. Segundo o editor responsável pela coleção de suas Obras Completas de Heidegger e seu último assistente, Friedrich-Wilhelm Von Herrmann, os textos que compõem a série dos Cadernos negros têm importância fundamental para a compreensão do pensamento de Heidegger em geral. Em 2003, muito antes do abalo sísmico que as afirmações antissemitas contidas nos Cadernos causariam, ele afirmara que:

caso de Heidegger sobretudo à luz dos fatos dos anos 30 e suas consequências. Sobre os paralelos entre Heidegger e Nietzsche cf. COLI, Heidegger e o problema da dor nos "Cadernos negros"; BABIC, Die Beiträge als Wille zur Macht. Nietzsche - Technik - Machenschaft. Sobre as articulações da metapolitica em Heidegger cf. GIUBILATO, O projeto de uma metapolítica nos Cadernos Negros de Heidegger (1931-1941).

13 HEIDEGGER, Einführung in die Metaphysik (GA 40), 40.

${ }^{14}$ HEIDEGGER, Einführung in die Metaphysik (GA 40), 40.

${ }^{15}$ A questão do antissemitismo filosófico ("metafísico", ou "onto-historial"), que aparece claramente nos Cadernos negros, foi discutida detalhadamente em TRAWNY, Heidegger e o mito da conspiração judaica mundial; DI CESARE, Heidegger e gli ebrei. I «Quaderni neri»; HOMOLKA \& HEIDEGGER (org.), Heidegger und der Antisemitismus; FABRIS (org.), Metafisica e antisemitismo. Sobre a topologia do pensamento onto-historial e a narração da história do Seer cf. IORIO, Das Sein erzählt. Heideggers narratives Denken; MALPAS, Heidegger and the Thinking of Place. Explorations in the Topology of Being.

${ }^{16}$ Cf. TRAWNY, Heidegger e o mito da conspiração judaica mundial. 
o que há aqui [nos Cadernos negros] é uma condensação do pensamento. [...]. Não se trata apenas de uma forma estilística distinta, mas neles [Heidegger] menciona muitas coisas que, tal como as escreveu, não escreveria em nenhum de seus outros ensaios, nem mesmo nos grandes. Por isso é que esses [...] volumes são de grande importância. Apenas quando tais volumes forem publicados e quando dele tivermos nos apropriado ao lê-los e ao refletir sobre eles é que poderemos vir a formar uma ideia final do pensador Martin Heidegger. Ainda que esses volumes não modifiquem radicalmente a imagem que temos dele, nos darão certamente uma nova perspectiva ${ }^{17}$.

É inegável que a publicação desse material nos obrigou à confrontação com uma perspectiva inteiramente distinta do pensador Heidegger - embora, para leitores mais atentos, não tão surpreendente ${ }^{18}$-, mesmo que essa revisão da "imagem final" da filosofia heideggeriana não seja do agrado de parte considerável de seus seguidores.

À primeira vista, chama a atenção o modo excessivamente acurado da escrita manuscrita do material dos Cadernos. Não há rasuras ou rabiscos, e a escrita é límpida como passada a limpo. Não se trata de anotações descuidadas, de um conjunto de rascunhos de ideias a elaborar. Trata-se, antes, de um material acabado,

\footnotetext{
17 Von Hermann, apud XOLOCOTZI, Facetas heideggerianas, 68.

${ }^{18}$ Muito embora a primeira grande polêmica envolvendo a relação de Heidegger com o nazismo tenha se formado em torno do trabalho de Victor Farías (publicado em 1987), essa associação já tinha sido apontada e problematizada anteriormente, remontando até mesmo a Jaspers (Philosophische Autobiographie, 1977) e Löwith, sem deixar de mencionar Adorno (Jargon der Eigentlichkeit, 1964). É de Löwith a irônica frase segundo a qual, após ouvir a conferência de Heidegger sobre $A$ auto-afirmação da universidade alemã (o famoso Discurso da reitoria), "após o discurso [de Heidegger] não se sabia se tomar os pré-socráticos de Diels pela mão ou se marchar junto às S.A." [“man am Ende des Vortrags nicht weiss, ob man Diels Vorsokratiker in die Hand nehmen soll oder mit der S.A. marschieren"] (Löwith, Mein Leben in Deutschland vor und nach 1933, 35). Dignos de nota são também os trabalhos de Derrida e LacoueLabarthe (ambos publicados no mesmo e fatídico ano de 1987), que antes mesmo da polêmica suscitada pelo trabalho pioneiro de Victor Farías, corajosamente enfrentaram inquietantes fatos até então restritos a aspectos biográficos de Heidegger. Se Derrida, em 1988 numa coluna ao Le Monde, classificou o "silêncio de Heidegger sobre seu passado" como "aterrador", Lacoue-Labarthe foi, por sua vez, visionário ao levantar a hipótese da relação entre a filosofia e o posicionamento político que levaram Heidegger à afiliação ao partido de Hitler, alegando que o "engajamento de Heidegger estava em absoluta coerência com seu pensamento". A publicação dos cursos ministrados por Heidegger em 1933-34, em 2001, [GA36/37: Sein und Wahrheit / 1. Die Grundfrage der Philosophie (semestre de verão 1933), 2. Vom Wesen der Wahrheit (semestre de inverno 1933/34)],gerou uma segunda onda de polêmicas em torno da questão 'Heidegger e o nazismo', ainda anterior à polêmica final causada pela publicação, em 2014, dos primeiros volumes dos Cadernos negros. Entre os expoentes da segunda onda, anterior aos Cadernos, podemos citar os trabalhos: FAYE, L'introduction du nazisme dans la philosophie, 2005; KIESEL, Heidegger's Gesamtausgabe. An international scandal of scholarship, 1995; VOLPI, Goodbye, Heidegger! Mi introducción censurada a los Beiträge zur Philosophie, 2011; KELLERER, Heideggers Maske. 'Die Zeit des Weltbildes' - Metamorphose eines Textes, 2015.
}

Voluntas, Santa Maria, v.12, n.1, p. 01-26, jan./abril., 2021 
cuidadosamente lapidado ao longo dos seus mais de quarenta anos de elaboração. Com efeito, os primeiros manuscritos datam de 1931, do início da fase caracterizada pelo pensamento onto-historial, e os últimos datam do mesmo ano de sua morte, em 1976. O irmão de Heidegger, Fritz Heidegger, faz menção a esses materiais em uma carta de 1950, na qual confirma sua importância e seu valor filosóficos no quadro geral do corpus da obra heideggeriana, a despeito de sua vastidão e diversificação. Ele escreve:

\begin{abstract}
Heidegger é inteiramente ele mesmo nesses manuscritos (não nas lições e conferências); eles estão aqui praticamente intactos, apenas alguns poucos foram transcritos. Neles aparece aquela atitude fundamental que deveria valer como princípio e fim de todo filosofar: eu a chamo há tempos de humildade. Nesses manuscritos estão escondidas as preciosidades e delícias do pensamento heideggeriano. Espero que elas permaneçam ocultas por muito tempo ${ }^{19}$.
\end{abstract}

O intuito de manter esse material oculto por muito tempo fora expresso pelo próprio Heidegger em uma nota autobiográfica datada de 1937-38, contemporânea à escrita de Contribuições à filosofia. Nesta nota, intitulada "Da preservação do que foi tentado"20, que chega a ser uma espécie de testamento espiritual, Heidegger menciona a existência de cadernos nos quais teria reunido "os estados de ânimo fundamentais do perguntar e as indicações das perspectivas as mais exteriores das tentativas de pensamento" 21 . Aparentemente surgidos de acordo com os instantes, eles [os materiais] contêm o ímpeto do esforço ininterrupto em torno da pergunta única."22 Aqui é evidente que a "pergunta única" a que se refere Heidegger diz respeito à pergunta que guia todo seu pensamento, que o atravessa e o caracteriza ao longo das diferentes fases de seu desenvolvimento, qual seja, a pergunta pelo ser: pelo sentido do ser em Ser e tempo, e pela verdade do Seer, entendida como a-letheia, a partir dos anos 1930. Em uma das primeiras aproximações hermenêuticas a esses textos, por

\footnotetext{
${ }^{19}$ Apud XOLOCOTZI, Facetas heideggerianas, 66.

20 Tradução livre. "Über die Bewahrung des Versuchten”, no original.

${ }^{21}$ HEIDEGGER, Besinnung (GA 66), 419.

22 HEIDEGGER, Besinnung (GA 66), 419.
} 
ocasião de um encontro ocorrido na Itália em julho de 2014, os intérpretes se recordaram de como "o próprio Heidegger decidiu, num gesto - certamente muito nietzschiano -, que esses manuscritos deveriam ser mantidos inacessíveis por pelo menos cem anos, tal como se sabe pelos testemunhos de Hermann Heidegger". ${ }^{23}$ Depois de muitas hesitações e incertezas, Heidegger finalmente decide, em 1973, que seus textos seriam publicados a partir do projeto que abrigaria e configuraria a estrutura de suas Obras Completas. Na disposição das obras tal como ele deixou indicada, os Cadernos negros seriam a obra final, a publicação derradeira que iluminaria todas as anteriores.

\section{ELEMENTOS PARA UMA HERMENÊUTICA DOS CADERNOS NEGROS}

Em uma indicação que provavelmente remonta ao início dos anos 1970, encontramos uma retrospectiva no mínimo curiosa sobre o conjunto dos textos dos Cadernos, e que pode nos servir como ponto de partida para o estabelecimento das ferramentas hermenêuticas necessárias à sua leitura: “as entradas dos cadernos negros são, em essência, tentativas do puro nomear - e não declarações ou mesmo notas para um sistema planejado" ${ }^{24}$. Essa referência aos Cadernos, recuperada pelo editor alemão entre materiais do começo dos anos 70 e inserida já no início do volume que inaugura a série dos Cadernos $\operatorname{Negros}^{25}$, nos revela pelo menos duas questões fundamentais. Em primeiro lugar, reitera que o material em questão não é um conjunto de anotações rascunhado mas, ao contrário, que se trata de uma obra, de um trabalho literário-filosófico planejado e executado como tal. Essa indicação já fora feita pelo editor geral das Obras Completas, ao que acrescenta, insistindo no aspecto de limpeza e clareza da grafia do material, que "existem milhares de folhas com anotações rápidas [de Heidegger], e por isso muito difíceis de decifrar. Isso não acontece nos Cadernos

\footnotetext{
23 ESCUDERO, Heidegger e i Quaderni Neri, 42.

${ }^{24}$ HEIDEGGER, Überlegungen II-VI (Schwarze Hefte 1931-1938) (GA 94), I.

${ }^{25} \mathrm{Cf}$. os esclarecimentos do editor da GA 94, Peter Trawny, no posfácio ao primeiro volume dos Cadernos: HEIDEGGER, Überlegungen II-VI (Schwarze Hefte 1931-1938) (GA 94), 529.
}

Voluntas, Santa Maria, v.12, n.1, p. 01-26, jan./abril., 2021 
Negros. Eles estão passados a limpo e a maior parte em boa caligrafia". ${ }^{26}$ Trata-se, evidentemente, de uma obra arquitetada com vistas à sua publicação, embora uma publicação concebível apenas sob condições muito especiais. Por mais desagradável que essa conclusão possa parecer para uma ala (significativa) de intérpretes da obra de Heidegger, recusar a relevância filosófica desse material sob o argumento que ele nada seria além de um diário de anotações pessoais é, para dizer o mínimo, um posicionamento questionável. Com efeito, o "caso Heidegger" torna evidente o perigo constante resultante do princípio hermenêutico da seleção ideológica entre obras "maiores" e "menores", o que, afinal, revela-se presa fácil de critérios demasiado subjetivos.

Em segundo lugar, a nota em que o editor dos Cadernos Negros resgata a visão que deles tinha o próprio Heidegger nos permite constatar seu desapreço por uma ideia de pensamento sistemático. Heidegger claramente não tinha nenhuma intenção de elaborar um sistema. Como afirmou Nietzsche em O crepúsculo dos ídolos, a vontade de sistema corresponderia à falta de honestidade - nessa acusação, Heidegger se revela verdadeira e radicalmente nietzschiano: em todas as caracterizações de Heidegger referidas aos Cadernos, o conceito de "intenção" e de "tentativa" [Versuch], opostos à estaticidade e imobilidade de um sistema filosófico, adquirem um significado essencial. Parece-nos imprescindível, portanto, reafirmar o respeito ao caráter afirmadamente assistemático e muitas vezes experimental do material aqui discutido.

Os Cadernos negros se apresentam, portanto, como tentativas, lances de experimentação filosófica através dos quais Heidegger exercia seu modo "tateante" de se aproximar de um pensamento mais originário, de dizer o indizível, de pensar o impensado. Nesse sentido, os textos dos Cadernos representam a mais alta realização das ambições de seu pensamento, expressa pela fórmula em execução no projeto de suas Obras Completas: "caminhos - não obras" [Wege - nicht Werke]. O caráter

\footnotetext{
${ }^{26}$ Von Herrmann apud XOLOCOTZI, Facetas heideggerianas, 68.
} 
assistemático marcado por "tentativas de pensamento" dos Cadernos concorda e confirma o caráter "errático" de um pensamento que está sempre "a caminho" [unterwegs], por "veredas ininterruptas" que não visam nem alcançam certezas inquestionáveis, mas que se nutrem de simples "sinais" de um itinerário a ser percorrido. Revela-se, assim, a tendência "pedagógica" - compreendida como condução ao caminho e ao exercício errático desse caminho - de um pensar que se afasta do pensar da filosofia à medida que recusa o caráter metafísico do pensar essencialmente representativo (vorstellendes Denken) e que pode, à diferença deste, ser compreendido como um be-wegendes Denken ${ }^{27}$, ou seja, um pensar movente, errante, que se movimenta pelos caminhos (Wege). O pensamento que faz do caminho (Weg) a própria prática, o próprio exercício que consiste, por sua vez, na contínua busca e tentativa (versuchen), na procura (Suche) e na pergunta (Frage) filosófica. A tentativa heideggeriana de superação e - podemos até mesmo dizer - de abandono - da tradição metafísica revela o potencial pedagógico e inovativo de um pensar que é o incessante exercício de percorrer os caminhos da experimentação e do exercício do próprio pensamento. Para sustentar textualmente essa leitura, podemos recorrer a uma das passagens que inauguram o volume Reflexões X (1938/39), da série dos Cadernos, no qual Heidegger afirma:

Estas e todas as "reflexões" anteriores não são "aforismos" nem "sabedorias de vida", mas modestos posicionamentos avançados e retaguardas, como o conjunto da tentativa de uma reflexão ainda indizível e com vistas à conquista de um caminho para o perguntar novamente inicial, o qual, à diferença do metafísico, atende pela denominação de pensamento onto-historial ${ }^{28}$.

Heidegger pontua uma diferença essencial em relação a Nietzsche e ao seu estilo de pensamento. Os Cadernos não são compostos de aforismos, mas de marcas de um esforço teórico que é o esforço da conquista de caminhos de pensamento que se distinguem e se afastam da metafísica ocidental, caminhos que podem nos levar a um "outro início" do pensamento. O perguntar mais original que nos conduz à exploração

\footnotetext{
27 HEIDEGGER, Anmerkungen VI-IX (Schwarze Hefte 1948/49-1951) (GA 98), 27.

${ }^{28}$ HEIDEGGER, Überlegungen VII-XI (Schwarze Hefte 1938/39) (GA 95), 274.
}

Voluntas, Santa Maria, v.12, n.1, p. 01-26, jan./abril., 2021 
de novos caminhos nos abre o horizonte do pensamento onto-historial, que se abre à história do Seer "todavia indizível". Seu dizer autêntico é o "silêncio". Como afirma Heidegger em suas Contribuições à filosofia, "o silenciamento [Erschweigung] é a 'lógica' da filosofia na medida em que ela pergunta pela questão fundamental a partir do outro início"29. Quanto mais necessário o dizer [Sagen] sobre o Seer [Seyn], mais inevitável se torna o silenciar [Erschweigen] da verdade do Seer ao longo do perguntar: “É impossível dizer imediatamente o Seer quando justamente se trata daquilo que é saltado no próprio salto. Pois todo dito provém do Seer e enuncia sua verdade. Toda palavra e, assim, toda lógica, estão sob o poder do Seer. A essência da 'lógica' é, portanto, a sigética. Apenas nela pode a essência da linguagem ser compreendida" ${ }^{30}$. As origens desta lógica sigética do pensamento do Seer estão presentes já em Ser e tempo, na ocasião em que Heidegger expressa a oposição radical do "muito falar sobre algo"31 do unoimpessoal, do "falatório do mundo"32 ao "calar-se" enquanto possibilidade essencial do falar e como "como modus do discorrer, <que> articula a entendibilidade do Dasein em um modo tão originário que é precisamente dele que provém o autêntico poder-ouvir e o transparente ser-um-com-o-outro"33.

Em um manuscrito datado dos anos 1973-75 e até há pouco inédito, pensado como um trabalho preparatório para uma ampla introdução (infelizmente nunca concluída) às suas Obras Completas, Heidegger faz uma importante advertência em relação aos Cadernos negros ao dizer que "um perigoso engano [Irrnis] ameaça os textos reunidos na seção IV sob o título 'Registros e Indicações'."34 E explica a seguir:

\footnotetext{
${ }^{29}$ HEIDEGGER, Beiträge zur Philosophie. Vom Ereignis (GA 65), 78.

${ }^{30}$ HEIDEGGER, Beiträge zur Philosophie. Vom Ereignis (GA 65), 79.

31 HEIDEGGER, Ser e tempo, 463.

32 HEIDEGGER, Ser e tempo, 465.

33 HEIDEGGER, Ser e tempo, 465.

34 HEIDEGGER, Eine gefährliche Irrnis, 11.
} 
Segundo a concepção habitual, espera-se encontrar aí notas casuais, folhas soltas, e até mesmo apenas ,materiais' para uma eventual ,obra' a ser realizada na forma de um texto contínuo. Esquece-se, nisso, que todo o conjunto da edição diz respeito apenas a um "caminho", e talvez apenas a vias e veredas que levam ao campo deste caminho, o caminho da questão única pelo Ser [Sein].

Refletindo sobre isso, devemos nos instruir de que a seção IV realiza o esforço de explicar os pontos decisivos da jornada que há décadas se faz, a saber, aquela indicada na Carta ao Humanismo como a "descida à pobreza“ do pensamento, que todavia ainda não foi alcançada: um dito do ser, por assim dizer sem forma, em meio a títulos distintos e em parte ainda provenientes da tradição ${ }^{35}$.

Os Cadernos representam, assim, "o decisivo" do caminho no silêncio do Seer, a escuta de sua palavra. Talvez por essa razão é que Heidegger introduz suas Anotações IV (textos referentes precisamente aos anos 1947/48) por meio de uma citação de Leibniz que diz assim: "Aquele que me conhece apenas por minhas publicações, não me conhece" ${ }^{36}$. O filósofo adverte seus leitores e intérpretes da necessidade de adentrar o oculto, o enigmático, aquilo que se esconde em seu pensamento. A esse último exercício, reservado aos iniciados em seu pensamento, foram reservados seus Cadernos negros como coroamento das Obras completas e, por conseguinte, do exercício de pensamento proposto por Heidegger. Sob essa perspectiva, a publicação desse material adquire um sentido muito particular. Poucas páginas após a citação de Leibniz, no mesmo volume, Heidegger afirma que:

A publicação de pensamentos essenciais numa época caracterizada pela ditadura da opinião pública adquire um sentido particular. Ela não pretende comunicar algo, mas pretende, através da má interpretação geral e da incompreensão apressada, sobretudo proteger-se ${ }^{37 !}$

O sentido da publicação do "essencial" não é a comunicação de alguma coisa específica, mas sua proteção em relação às más interpretações por parte daqueles que se mostram incapazes de escutar "o simples nomear" 38 deste novo e mais radical

\footnotetext{
35 HEIDEGGER, Eine gefährliche Irrnis, 11.

${ }^{36}$ HEIDEGGER, Anmerkungen I-V (Schwarze hefte 1942-48) (GA 97), 325.

37 HEIDEGGER, Anmerkungen I-V (Schwarze hefte 1942-48) (GA 97), 411.

38 HEIDEGGER, Überlegungen II-VI (Schwarze Hefte 1931-1938) (GA 94), I.
} 
perguntar. É interessante notar que Heidegger afirma algo muito semelhante em relação aos cursos sobre Nietzsche dos anos 1936 a 1940:

Minhas preleções sobre a metafísica de Nietzsche dos anos 1936-1940 têm a única intenção de deixar reconhecer a valência da essência da metafísica no pensamento de Nietzsche e, assim, compreender que e como a metafísica aí se conclui; isso só foi possível, segundo o procedimento geral de minhas preleções, a partir da gama de ideias circulantes, e sem dúvida, de fato, apenas no silenciado e a partir do que foi dito no pensamento da verdade do $\operatorname{ser}^{39}$.

Essa mesma ideia é reforçada ainda em várias passagens dos Cadernos, escritas no outono de 1932. Heidegger se impõe o desafio de "não dizer imediatamente e tampouco escrever 'sobre' - Heráclito - Kant - Hölderlin - Nietzsche" ${ }^{40}$, os quais representariam as figuras essenciais e epocais da história do Seer, "mas, em oculto agradecimento, transformar tudo em potência e força; e só então - caso dê certo restituí-los como completos estranhos à grandeza do mais próprio"41. O princípio que rege o pensamento onto-historial de Heidegger parece ser, portanto, o esoterismo cuja máxima é "preservar o obscuro do claro" 42 - segundo a fórmula que consta como epígrafe nas anotações de 1934-35. Dito de outro modo: “o essencial deve permanecer silenciado, agora e futuramente" 43 . O falar ao se calar surge aqui como um dos princípios do pensamento heideggeriano a partir da década de 1930 e o caracteriza com traços tipicamente esotéricos. ${ }^{44}$

\footnotetext{
39 HEIDEGGER, Anmerkungen I-V (Schwarze hefte 1942-48) (GA 97), 395.

40 HEIDEGGER, Überlegungen II-VI (Schwarze Hefte 1931-1938) (GA 94), 169.

${ }^{41}$ HEIDEGGER, Überlegungen II-VI (Schwarze Hefte 1931-1938) (GA 94), 169.

42 HEIDEGGER, Überlegungen II-VI (Schwarze Hefte 1931-1938) (GA 94), 205.

${ }^{43}$ HEIDEGGER, Überlegungen II-VI (Schwarze Hefte 1931-1938) (GA 94), 88.

${ }^{44}$ Cf. TRAWNY, Adyton: A filosofia esotérica de Heidegger; VOLPI; La selvaggia chiarezza, 276-279.
} 


\section{A FIGURA DE NIETZSCHE NOS CADERNOS NEGROS}

A exposição a seguir sobre Nietzsche e seu papel nos Cadernos faz referência apenas aos primeiros quatro volumes dos Cadernos, os quais se estendem de 1931 a 1948. Nesse conjunto de textos, Heidegger ressalta Nietzsche como o mais impetuoso e feroz opositor da modernidade e de sua "racionalidade do cálculo", a qual teria assumido dimensões planetárias por meio do fenômeno da técnica. Os Cadernos seriam, nesse contexto, a tentativa - por vezes de uma violência cruel - de combater o "crescente deserto" já denunciado por Zaratustra, i.e., de batalhar contra o "desencantamento do mundo", recorrendo a todos os meios à disposição, filosóficos e não filosóficos, e demonstrando o caráter fantasmagórico da moral do perdão e da vingança, sobretudo nos volumes escritos depois dos eventos catastróficos da guerra, no momento em que predominava o sentimento de reconstrução da sociedade alemã. Poderíamos dizer, assim, que Heidegger, enquanto discípulo de Zaratustra, estava determinado a "defender o essencial até às últimas consequências" 45 contra a maquinação do ente e sua hegemonia na época moderna. Ele então prontamente se pergunta:

Não teríamos, por acaso, nem intuído e tampouco apreendido - e estaríamos realmente decididos a chegar às últimas consequências? Para nomear apenas um: Nietzsche! Ele é arbitrariamente e acidentalmente saqueado, mas a isso nenhum esforço de elevar sua vontade mais íntima a fundamento, de colocá-la em funcionamento e trazê-la para o caminho [se contrapõe] ${ }^{46}$.

O nome de Nietzsche define aquele espaço oculto do "essencial" que constitui o "mais íntimo querer" da filosofia de Heidegger e de seu "simples nomear". Outra confirmação do papel fundamental que Nietzsche desempenhou na história da metafísica e de sua vinculação ao pensamento essencial pode ser encontrada na seguinte passagem: "Depois de Hölderlin e depois de Nietzsche, já não há, para os alemães, nem poesia nem pensamento que pudesse ainda ser essencial - que

\footnotetext{
45 HEIDEGGER, Überlegungen II-VI (Schwarze Hefte 1931-1938) (GA 94), 39.

${ }^{46}$ HEIDEGGER, Überlegungen II-VI (Schwarze Hefte 1931-1938) (GA 94), 39.
}

Voluntas, Santa Maria, v.12, n.1, p. 01-26, jan./abril., 2021 
fundamentasse o decurso histórico em insurgência com o Deus [...] e por isso mesmo é que o afastamento diante deles [dos deuses] e o abandono do poetar e do pensar torna-se algo habitual"47.

Mais que isso, Nietzsche representa a essência do filósofo solitário, aquele que, guardando o silêncio de muitos anos, abriu-se à perspectiva de um novo caminho, de um outro pensar. Heidegger não quer se resignar nem se acostumar à "ausência" de grandes e verdadeiros pensadores. Pode-se mesmo dizer que a figura de Nietzsche representa o pai espiritual de Heidegger naqueles anos ou, ainda, seu legítimo precursor, com o qual Heidegger estaria em relação direta de filiação na dinâmica dos "ocultamentos e desvelamentos" [Verbergung-Entbergung] que caracteriza a história do Seer. Em uma nota extraordinária, intitulada "O lúdico e o aterrorizante nos números da cronologia historiográfica em primeiro plano da história abissal da Alemanha ${ }^{48}$, Heidegger expõe a genealogia das grandes figuras do pensamento que, segundo ele, marcaram os momentos mais significativos da relação entre Seer e Dasein, entre acontecimento apropriativo e existência humana singular. Seriam esses:

1806 Hölderlin parte e soleva-se uma congregação alemã.

18130 arranque alemão atinge seu apogeu e nasce Richard Wagner.

1843 Hölderlin deixa o "mundo" e Nietzsche a ele chega um ano depois.

1870/76 Estabelece-se na Alemanha os "Anos de fundação" e surgem as Considerações Extemporâneas de Nietzsche.

1883 A primeira parte de Zaratustra é publicada e morre Richard Wagner.

1888 Final de dezembro: a „euforia“ de Nietzsche antes do colapso e -

$(26.9 .1889)^{49}$.

O dia 26 de setembro de 1889 é, como se sabe, a data do nascimento de Martin Heidegger. Como tal, ela marcaria o momento da passagem do testemunho da

\footnotetext{
${ }^{47}$ HEIDEGGER, Überlegungen VII-XI (Schwarze Hefte 1938/39) (GA 95), 30.

48 HEIDEGGER, Überlegungen II-VI (Schwarze Hefte 1931-1938) (GA 94), 523.

49 HEIDEGGER, Überlegungen II-VI (Schwarze Hefte 1931-1938) (GA 94), 523
}

Voluntas, Santa Maria, v.12, n.1, p. 01-26, jan./abril., 2021 
mensagem onto-historial, a passagem de uma herança espiritual: na disposição esotérica de Heidegger, a figura de Nietzsche é aquela que abre o caminho ao novo pensar da história esquecida e oculta do Seer. Mas por que Nietzsche? Ora, Nietzsche teria sido o único a antever a dimensão da catástrofe mundial que então já se anunciava e a estimar a corrosão que o niilismo seria capaz de promover nos fundamentos da civilização europeia. Ele teria sabido antever um novo caminho. "Apenas Nietzsche viu e pôde ver a "situação atual" - porque ele anteviu algo Outro"50. E, assim, ele teria alicerçado a postura daquele que olha à frente munido de niilismo ativo e exige uma decisão nova para um início renovado e renovador. Mesmo que esse trabalho "além do humano" tenha sobrepujado o homem Nietzsche, sua figura marca uma virada na história do pensamento na medida em que marca o fim que se realiza enquanto promessa de um novo início da história do Seer. Mas esse significado de fim/início da obra nietzschiana restaria ainda a ser compreendido, segundo Heidegger:

\begin{abstract}
Se os hodiernos, e especialmente os estudiosos profissionais de "filosofia" tivessem se dado conta de que Nietzsche falara, então o escrever e o falar sobre filosofia teriam que ter sido imediatamente interrompidos, e um silenciar que se prolongaria por anos teria de ser decretado para testemunhar que os alemães estariam começando a compreender seus pensadores mais visionários. Em vez disso, a 'escrivinhação' pulula até o incalculável [...] Mais uma vez estamos no reino de legislação do ruído desmedido ${ }^{51}$.
\end{abstract}

A figura de Nietzsche surge como um campo de forças no qual se insinua a contemporaneidade: foi ele o arauto da inversão do platonismo, a derrocada do mundo verdadeiro projetado no suprassensível. O mundo aparente do sensível assumiu as vezes de mundo "mundo verdadeiro", absorvendo, para o conceito de mundo, toda a instabilidade e potência daquilo que almeja a constante superação de si mesmo. Essa virada, por mais que ainda tributária dos princípios do platonismo ao estabelecer com ele uma relação de oposição, contém em si a forma estimulante para questioná-la e superá-la. Para Heidegger, portanto, a virada anunciada na filosofia de Nietzsche não diz respeito a um movimento de rotação, a um curto circuito do

\footnotetext{
50 HEIDEGGER, Überlegungen II-VI (Schwarze Hefte 1931-1938) (GA 94), 49.

${ }^{51}$ HEIDEGGER, Überlegungen II-VI (Schwarze Hefte 1931-1938) (GA 94), 349.
}

Voluntas, Santa Maria, v.12, n.1, p. 01-26, jan./abril., 2021 
18 |A figura de Nietzsche nos Cadernos Negros (1931-1948) de Heidegger. Uma abordagem hermenêutica

pensamento metafísico mas, antes, anuncia aquela transição que tanto pontua o fim quanto aponta para um recomeço inteiramente distinto, o qual, na condição de "outro início", situa o primeiro início em si mesmo de um modo originário no gesto mesmo em que o nega. A figura de Nietzsche percorre e alicerça, portanto, o grande interlúdio entre o primeiro início e um segundo início que o retoma e nega, uma vez que é nele que tudo se enraíza. A virada que possibilita o encontro de um primeiro e de um segundo início se realiza à medida que “Nietzsche se volta ao início da filosofia ocidental; o qual é, todavia, e justamente, seu fim. E só então deve-se poder dizer: Incipit principium!"52. Apenas assim esse novo principiar do início se revela como necessário [notwendig], dirigido à experiência da indigência [Not-wendig], experiência radical da precariedade do abandono do Seer [Seyn], que Nietzsche experimentou e reconheceu como niilismo. Assim é que a obra mais esotérica de Nietzsche, Assim falou Zaratustra, representa para Heidegger "um clamor, talvez o grito, [...] que sinaliza que aqui se anuncia uma transição - o arco único de uma ponte cujos pilares permanecem invisíveis, razão pela qual a oscilação do arco traça seu curso de modo ainda mais vibrante" $^{\prime 53}$. Com seu pensamento, Nietzsche teria se adiantado e adentrado aquele

\footnotetext{
52 HEIDEGGER, Überlegungen II-VI (Schwarze Hefte 1931-1938) (GA 94), 189. Essas passagens dão testemunho da transformação que sofre a figura de Nietzsche ao longo do desenvolvimento do pensamento heideggeriano. Se nas famosas Preleções sobre Nietzsche dos anos 1939-1946, Heidegger apresenta um Nietzsche muito mais "prisioneiro" da tradição metafísica e de sua "inversão dialética", o Nietzsche que surge dessas passagens é, antes, o arauto cuja função histórica é a de "anunciar" e "apontar" para o caminho da inauguração possível de uma nova experiência do Seer. A mudança de perspectiva em relação à figura de Nietzsche, que Lacoue-Labarthe e Derrida (cf. WOLIN, Heidegger et le nazisme, 126) atribuíram justamente à confrontação (mesmo teórico-filosófica) de Heidegger com o Nacional-Socialismo em geral - com a figura de Hitler, em particular, até aproximadamente 1932, e com o partido até pouco depois - encontra nesses materiais dos Cadernos negros sua confirmação textual: se o Nietzsche do final das Preleções permanece "prisioneiro" da tradição metafísica e de sua "inversão dialética", o Nietzsche que Heidegger apresenta nesse recorte dos Cadernos surge como o elemento decisivo de subversão do niilismo ao qual os valores tradicionalmente ocidentais nos teriam conduzido. Nesse sentido, a mudança de perspectiva em relação à função que Nietzsche desempenha na arquitetura heideggeriana da história do Seer sofre um processo semelhante - e paralelo - ao contexto geral do problema da técnica, como muito bem documentado no artigo de KELLERER, Heideggers Maske. 'Die Zeit des Weltbildes' - Metamorphose eines Textes. Deixaremos essa questão, todavia e convenientemente, para uma ocasião futura.

${ }^{53}$ HEIDEGGER, Überlegungen II-VI (Schwarze Hefte 1931-1938) (GA 94), 349.
}

Voluntas, Santa Maria, v.12, n.1, p. 01-26, jan./abril., 2021 
deserto de desolação e devastação instaurado pela modernidade, seu poder incondicional de "maquinação" do ente e a preponderância do caráter exclusivamente subjetivo do animal "humano". Esse deserto, descoberto por antecipação e aberto paulatinamente, seria ainda a razão oculta do caráter arrebatador do pensamento nietzschiano. O deserto que Nietzsche soube antever simbolizaria, assim, o implacável "encalhar-se nas areias" da barcaça, já descontrolada, da metafísica ocidental, a dissipação de todas as possibilidades de "decisão" e "revolução transformadora" que a teriam conduzido à sua culminação catastrófica e de dimensões planetárias. Esse "serjá-decidido", assim determinado pela impossibilidade de qualquer decisão e transformação ulterior, está anunciado, segundo Heidegger, na teoria do eterno retorno de Nietzsche, uma vez que ela representaria "o que há de mais final no fim da metafísica ocidental - o último que de metafísico pôde e teve de ser pensado no ocidente - o pensamento de todos os pensamentos de Nietzsche ${ }^{54}$.

Nesse contexto, Heidegger denuncia que a dimensão pública e seu "ruidoso falatório" já teriam se apropriado diabolicamente da figura de Nietzsche, imitando e enfraquecendo o discurso sobre a superação [Überwindung] da metafísica, apresentado por Nietzsche em Humano demasiado humano. No entanto, na perspectiva de Heidegger, Nietzsche teria alcançado apenas uma inversão [Umdrehung] da metafísica, e "apenas" aqui diz respeito ao sentido de sua realização: apenas da realização da metafísica é que pode advir sua superação, segundo Nietzsche. Para Heidegger, no entanto, a superação não é o último estágio, mas o penúltimo momento do processo, como o elevar-se acima [Verwindung] da metafísica. Assim é que Nietzsche representaria o lugar extremo e mais perigoso do pensamento que se apresenta como a superação da metafísica quando, na realidade, alcançou apenas sua inversão. A mera inversão, por sua vez, estaria sempre confrontada ao risco de, paradoxalmente, realizar a consolidação e afirmação da própria metafísica ${ }^{55}$.

\footnotetext{
${ }^{54}$ HEIDEGGER, Überlegungen XII-XV (Schwarze Hefte 1939-1941) (GA 96), 14.

${ }^{55}$ Cf. HEIDEGGER, Überlegungen II-VI (Schwarze Hefte 1931-1938) (GA 94), 328.
} 
As razões do fracasso de Nietzsche em ir além da inversão da metafísica e consolidar o "outro início" residiriam, ainda segundo Heidegger, na mesma dialética antiplatônica de seu modo de pensamento. Toda antítese está necessariamente referida e ligada àquilo que, enquanto movimento oposto, ela pretende superar. Toda antítese está, em última instância, conectada ao seu oposto e àquilo a que ela se opõe. Esse princípio marca o comprometimento de Nietzsche com o projeto do platonismo à medida de sua intenção de invertê-lo e de se opor a ele. A pergunta pela verdade do Seer, segundo Heidegger, não deve ser compreendida enquanto antítese à pergunta fundamental de toda metafísica ocidental, a saber, o que é o ente?, mas como a pergunta capaz de se diferenciar a ponto de não se colocar "contra" a metafísica, mas "para" ou "a favor" da metafísica, o que evidentemente não significaria sua imediata afirmação, mas sua transformação em uma necessidade mais simples: a metafísica compreendida como a história do desvelamento e do ocultamento do Seer. É nesse contexto que Nietzsche surge como o grande "inversor", aquele que leva a cabo a inversão [Umkehrung] fundamental que, embora jamais corresponda a um regresso [Zukehrung] ou volta à origem, instauraria o verdadeiro acontecimento epocal: "Por que não podemos simplesmente saltar essa inversão? Porque o invertido ficaria, assim, conservado nela" ${ }^{56}$. O além-do-humano de Nietzsche representaria, aos olhos de Heidegger, a última determinação do humano enquanto animal - não racional, mas como animal que não foi ainda completamente estabelecido [das noch nicht festgestellte Tier]. Assim,

O além-do-humano de Nietzsche é a última e primeira determinação do "humano" como animal ainda não inteiramente estabelecido - a afirmação máxima da metafísica em sua inversão enquanto seu acabamento e conclusão, e enquanto regresso final - não inicial - ao início da história do humano ocidental ${ }^{57}$.

\footnotetext{
56 HEIDEGGER, Überlegungen VII-XI (Schwarze Hefte 1938/39) (GA 95), 327.

57 HEIDEGGER, Überlegungen VII-XI (Schwarze Hefte 1938/39) (GA 95), 437-438. Não seria possível discutir aqui, nos limites de um artigo, as características e os limites da interpretação heideggeriana de Nietzsche; todavia vale mencionar, a respeito da noção de Übermensch (o Além-do-humano) que, embora ela apareça como uma figura fundamental na leitura proposta por Heidegger, no contexto da
} 
Os Cadernos negros nos mostram a figura de Nietzsche como o marco que assinala o "final do primeiro início" e, nesse sentido, Nietzsche se revela como a figura de transição, que encerra algo ao mesmo tempo em que cria a possibilidade de seu recomeço. Nietzsche é, portanto, uma

\begin{abstract}
preparação de um outro início da história do Seer. [...] Nietzsche é uma transição apenas no sentido de que ele antecipa metafisicamente a finalização da Modernidade e estabelece, assim, seu fim - e, por meio desse fim, o qual ele mesmo não reconheceu enquanto tal e ignorou, justamente por ainda pensar metafisicamente como o último e definitivo pensador, coloca à disposição a possibilidade de uma preparação para a decisão por um outro início ${ }^{58}$.
\end{abstract}

Pensado através de Heidegger e a partir da essência onto-historial da metafísica em sua totalidade, a filosofia de Nietzsche tem o caráter decisivo do presságio que antecede a abertura ao movimento que caracteriza o outro início ao realizar supremamente o fim do movimento anterior. Se Nietzsche representa o fim da metafísica, mesmo sendo, ele próprio, um metafísico, seu pensamento tem a importância histórica de anunciar o começo da superação essencial da metafísica e de abrir as vias para a reconfiguração do pensamento filosófico. Esta seria, segundo Heidegger, a posição histórica fundamental ocupada pela figura de Nietzsche

\title{
CONCLUSÃO
}

Nietzsche acreditou poder substituir a consciência e a lógica por meio da reafirmação das pulsões e do corpo. Não soube ver, no entanto, que mesmo as pulsões, enquanto determinações humanas, têm a mesma origem que as representações de consciência. A consequência da antropologia de Nietzsche, de sua destruição do sujeito enquanto "máscara", bem como da racionalidade enquanto dissolução da ratio na mera fisiologia e no jogo das pulsões, seria, ainda assim, uma apelação dogmática à vida enquanto única e última realidade. Mas se a razão e a subjetividade não são nada mais

filosofia de Nietzsche ela poderia mesmo ser lida como uma "contra-figura" que, tão logo aparece, prontamente é abandonada, substituída por outras.

${ }^{58}$ HEIDEGGER, Überlegungen XII-XV (Schwarze Hefte 1939-1941) (GA 96), 11.

Voluntas, Santa Maria, v.12, n.1, p. 01-26, jan./abril., 2021 
que um epifenômeno da dinâmica vital da vontade de poder, isso, segundo Heidegger, não conduziria para além de uma simples inversão do platonismo, e portanto de uma mera reformulação da metafísica da subjetividade, agora invertida numa metafísica do vitalismo e dos instintos. Por isso, denunciando as limitações do Übermensch nietzschiano, Heidegger considera que uma transformação da essência do ser humano só é possível quando a primeira de suas determinações ocidentais enquanto animal racional é desarraigada, arrancada pela raiz, i.e., apenas quando se questiona radicalmente as possibilidades originárias da determinação essencial do humano $a$ partir de seu pertencimento ao evento do Seer.

Em última instância, podemos concluir essa breve apresentação da figura de Nietzsche nos materiais que compõem os Cadernos negros de Heidegger afirmando que Heidegger reconhece as razões do diagnóstico nietzschiano da enfermidade que assola a época moderna, muito embora eles não estejam de acordo em relação àquele que seria o melhor tratamento a tal enfermidade:

\begin{abstract}
A superação decisiva de Nietzsche (distinto de algo como a sempre tão nãofilosófica 'refutação') jamais poderia ser imediatamente realizada; esta consistiria, antes, no abalo (na retirada dos fundamentos) da metafísica ocidental enquanto tal; através disso, a definição tanto 'de vida' como de ente tornam-se sem-fundamento, sem-chão [bodenlos] - visto que, assim, o 'ente' perde sua primazia. Superada essa abordagem 'de vida', cai por terra aquilo que supostamente constituiria seu caráter de ente [Seiendheit]: a vontade de potência e o que preenche seu modo de ser: o eterno retorno. A superação da metafísica é o abalo do platonismo [...] <assim como o é> toda forma de inversão do platonismo ${ }^{59}$.
\end{abstract}

As "ferramentas" das quais se serve o pensamento onto-historial heideggeriano para violentar a tradição metafísica ocidental não seriam, portanto, nem “o martelo"60 - do qual se serviu Nietzsche em O crepúsculo dos ídolos para quebrar os últimos absolutos das pretensões filosóficas após a morte de Deus - nem "a foice" ${ }^{61}$, provavelmente símbolo referido às ideias estruturadas sob a base do materialismo

\footnotetext{
59 HEIDEGGER, Überlegungen VII-XI (Schwarze Hefte 1938/39) (GA 95), 91

${ }^{60}$ HEIDEGGER, Anmerkungen I-V (Schwarze hefte 1942-48) (GA 97), 511.

${ }^{61}$ HEIDEGGER, Anmerkungen I-V (Schwarze hefte 1942-48) (GA 97), 511.
} 
histórico (com as quais flertavam tantos de seus leitores e intérpretes, pensemos sobretudo em Sartre) e às propostas revolucionárias ligadas a ele. Após a "virada", e após os anos furiosos de experimentação e "expansão para além e fora do $\log _{0 \text { " }}$ "62 do pensamento do Seer, a reflexão heideggeriana se retira e se refugia no simples escutar e nomear da palavra do Seer, nas formas e na prática de um "outro pensar", na dimensão meditativa e poética da serenidade [Gelassenheit], que afirma que "não devemos fazer absolutamente nada, apenas esperar". ${ }^{63} \mathrm{Em}$ um gesto tipicamente teatral e metafórico, Heidegger afirma a necessidade de abandonar "foice e martelo" diante da consideração de que o "arado", com o qual se abre, a terra, o espaço para o semeio do "campo do mundo", é mais importante e mais originário que a ação do martelo ou da foice, ainda dialeticamente presa naquilo ingenuamente creem poder subverter. Heidegger tem plena consciência e compreensão das razões onto-historiais do fato de que "Nietzsche foi ainda obrigado a filosofar com o martelo e tentar martelar tanto o eterno retorno do mesmo quanto o ser do ente, e firmar o humano de modo que ele pudesse suportar tudo isso e daí tirar suas medidas"64. Porém, em 1945, após mais de 10 anos de luta e confrontação ininterrupta com o pensador mais extremo da metafísica, Heidegger finalmente lograva estabelecer a distância em relação a Nietzsche e mover-se na nova via assinalada por ele, Nietzsche, ao demarcar o extremo da finda metafísica: "da virada do esquecimento do Seer acontece o inevitável: cultivar primeiro a lavoura do mundo para deixá-la pronta para o plantio, ao sol e à chuva e aos pássaros do céu"65.

Após uma confrontação radical e destrutiva com Nietzsche ao longo de toda a década de 1930, Heidegger finalmente o supera, o digere e o assimila, para inaugurar aquele "espaço do pensamento e da palavra" que chamará mais tarde de serenidade [Gelassenheit], em referência àquela atitude de abandono da metafísica ao seu destino,

\footnotetext{
${ }^{62}$ Cf. DI BLASI, Außerhalb des Logos. Die Expansion des seinsgeschichtlichen Antisemitismus.

63 HEIDEGGER, Feldweg-Gespräche (1944-45) (GA 77), 110: "Wir sollen gar nichts tun, sondern warten".

${ }^{64}$ HEIDEGGER, Anmerkungen I-V (Schwarze hefte 1942-48) (GA 97), 511.

65 HEIDEGGER, Anmerkungen I-V (Schwarze hefte 1942-48) (GA 97), 511.
} 
sem mais aceitar a disposição de escutar toda sua ruidosa falação e tampouco de usar sua linguagem objetivadora. Nietzsche, assim, anunciara o novo caminho quando, em seu prólogo de 1886 à obra Humano demasiado humano, lembrava que "em certos casos, como diz o provérbio, só se permanece filósofo — mantendo o silêncio"66.

\section{REFERÊNCIAS}

BABIC, B. Die Beiträge als Wille zur Macht. Nietzsche - Technik - Machenschaft. In: BABIC, Babette. "Ein Gottes Glück voller Macht und Liebe": Beiträge zu Nietzsche, Hölderlin, Heidegger. Weimar: Bauhaus-Universitätsverlag, 2009.

COLI, A. L. Heidegger e o problema da dor nos "Cadernos negros". Natureza Humana, 18/1 (2016), 21-36.

DERRIDA, J. De l' esprit: Heidegger et la question. Paris: Galilée, 1987.

DI CESARE, A. Heidegger e gli ebrei. I «Quaderni neri». Bologna: Bollati Boringhieri, 2014.

ESCUDERO, J. A. Heidegger e i Quaderni Neri. In: FABRIS, Adriano (Org.). Metafisica e antisemitismo. Pisa: ETS, 2014.

FABRIS, A. (Org.). Metafisica e antisemitismo. Pisa: ETS, 2014.

FARÍAS, V. Heidegger et le Nazisme. Paris: Verdier, 1987. | Heidegger e o nazismo - Moral e Política. Trad. Sieni Maria Campos. Rio de Janeiro: Paz e Terra, 1988.

FAYE, E. F, E. Heidegger, L'introduction du nazisme dans la philosophie. Paris: Albin Michel, 2005.

GADAMER, H-G. Verdade e método. Trad. Flávio Paulo Meurer Petrópolis: Vozes, 1999.

GIUBILATO, G. J. O projeto de uma metapolítica nos Cadernos Negros de Heidegger (1931-1941). Natureza Humana, 21/1 (2016), 73-83.

HEIDEGGER, M. Einführung in die Metaphysik (GA 40). Frankfurt: Klostermann, 1983.

HEIDEGGER, M. Beiträge zur Philosophie. Vom Ereignis (GA 65). Frankfurt: Klostermann, 1989. HEIDEGGER, M. Carta sobre o humanismo. Trad. Emmanuel Carneiro Leão. Rio de Janeiro: Tempo Brasileiro, 1995.

66 NIETZSCHE, Humano, demasiado humano, 14. 
HEIDEGGER, M. Feldweg-Gespräche (1944-45) (GA 77). Frankfurt: Klostermann, 1997.

HEIDEGGER, M. Besinnung (GA 66). Frankfurt: Klostermann, 1997.

HEIDEGGER, M. Eine gefaerliche Irrnis. Meßkirch: Martin-Heidegger-Gesellschaft, 2008.

HEIDEGGER, M. Ser e tempo. Trad. Fausto Castilho. Petrópolis: Vozes, 2012.

HEIDEGGER, M. Überlegungen II-VI (Schwarze Hefte 1931-1938) (GA 94). Frankfurt: Klostermann, 2014a.

HEIDEGGER, M. Überlegungen VII-XI (Schwarze Hefte 1938/39) (GA 95). Frankfurt: Klostermann, 2014b.

HEIDEGGER, M. Überlegungen XII-XV (Schwarze Hefte 1939-1941) (GA 96). Frankfurt: Klostermann, 2014c.

HEIDEGGER, M. Anmerkungen I-V (Schwarze hefte 1942-48) (GA 97). Frankfurt: Klostermann, 2015.

HEIDEGGER, M. Anmerkungen VI-IX (Schwarze Hefte 1948/49-1951) (GA 98). Klostermann, Frankfurt, 2018.

HEIDEGGER, M. \& JASPERS, K. Correspondencia (1920-1963). Madrid: Síntesis, 2003.

HOMOLKA, W. \& HEIDEGGER, Arnulf (org.). Heidegger und der Antisemitismus. Positionen im Widerstreit. Freiburg: Herder, 2016.

IORIO, A. Das Sein erzählt. Heideggers narratives Denken. Frankfurt: Klostermann, 2017.

KELLERER, S. Heideggers Maske. 'Die Zeit des Weltbildes' - Metamorphose eines Textes. Idee - Zeitschrift für Ideengeschichte, 3/1 (2015), 109-120.

KIESEL, T., Heidegger's Gesamtausgabe. An international scandal of scholarship. Philosophy Today, 39/1 (1995), 3-15.

LACOUE-LABARTHE, P. La fiction du politique: Heidegger, l'art et la politique. Paris: Association de publications, 1987.

LÖWITH, K. Mein Leben in Deutschland vor und nach 1933. Stuttgart: Metzler, 2007.

MALPAS, J. Heidegger and the Thinking of Place. Explorations in the Topology of Being. Cambridge, MA: The MIT Press, 2012.

NIETZSCHE, F. Humano, demasiado humano. Trad. Paulo César de Souza. Companhia das letras: São Paulo, 2005. 
TRAWNY, P. Adyton: a filosofia esotérica de Heidegger. Trad. Marcia Sá Cavalcante Schuback. Rio de Janeiro: Mauad X, 2013.

TRAWNY, P. Heidegger e o mito da conspiração judaica mundial. Rio de Janeiro: Mauad, 2015.

TRAWNY, P. Heidegger e o mito da conspiração judaica mundial. Trad. Soraya Guimarães Hoepfner. Rio de Janeiro: Mauad X, 2015.

VOLPI, F. Goodbye, Heidegger! Mi introducción censurada a los Beiträge zur Philosophie. Fenomenología y Hermenéutica. Acta del I Congreso International de Fenomenología y Hermenéutica. Santiago del Chile, 2008, 43-63.

VOLPI, F. La selvaggia chiarezza. Scritti su Heidegger. Milano: Adelphi, 2011.

XOLOCOTZI, Á. Facetas heideggerianas. Puebla: Libros de Homero, 2009.

WOLIN, R. Heidegger et le nazisme. L'Homme et la société, 97/1 (1990), 119-131.

\section{Contribuição de autoria}

\section{1 - Anna Luiza Coli}

Professora e Pesquisadora

https://orcid.org/0000-0003-3008-754•annaluizacoli@gmail.com

Contribuição: Escrita - Primeira Redação

\section{2 - Giovanni Jan Giubilato}

Professor de Filosofia

https://orcid.org/0000-0002-0305-6662•giovannijangiubilato@hotmail.com

Contribuição: Escrita - Primeira Redação

\section{Como citar este artigo}

COLI, Anna Luiza e GIUBILATO, Jan Giovanni. A figura de Nietzsche nos Cadernos Negros (19311948) de Heidegger. Uma abordagem hermenêutica. Voluntas Revista Internacional de Filosofia, Santa Maria, v. 12, n.1, e7, 2021. DOI 10.5902/2179378664684. Disponível em: https://doi.org/10.5902/2179378664684. Acesso em: dia mês abreviado. ano. 